\title{
Sarcopenic Obesity in Heart Failure With Preserved Ejection Fraction
}

\author{
Danielle L. Kirkman, Natalie Bohmke, Hayley E. Billingsley and Salvatore Carbone*
}

Department of Kinesiology and Health Sciences, College of Humanities \& Sciences, Virginia Commonwealth University, Richmond, VA, United States

Heart failure with preserved ejection fraction (HFpEF) is a public health epidemic that is projected to double over the next two decades. Despite the high prevalence of HFpEF, there are currently no FDA approved therapies for health-related outcomes in this clinical syndrome making it one the greatest unmet needs in cardiovascular medicine. Aging and obesity are hallmarks of HFpEF and therefore there is a high incidence of sarcopenic obesity (SO) associated with this syndrome. The presence of SO in HFpEF patients is noteworthy as it is associated with co-morbidities, worsened cardiovascular health, hospitalizations, quality of life, and mortality. Furthermore, SO plays a central role in exercise intolerance, the most commonly reported clinical symptom of this condition. The aim of this review is to provide insights into the current knowledge pertaining to the contributing pathophysiological mechanisms and clinical outcomes associated with HFpEF-related SO. Current and prospective therapies to address SO in HFpEF, including lifestyle and pharmaceutical approaches, are discussed. The urgent need for future research aimed at better understanding the multifaceted physiological contributions to $\mathrm{SO}$ in HFpEF and implementing interventional strategies to specifically target SO is highlighted.

Reviewed by:

Peter H. Brubaker,

Wake Forest University, United States Shane Nanayakkara,

Alfred Hospital, Australia

*Correspondence: Salvatore Carbone scarbone@vcu.edu

Keywords: sarcopenia, obesity, heart failure, diastolic, exercise tolerance, quality of life, nutrition, exercise training

\section{INTRODUCTION}

Heart failure (HF) is a rapidly growing public health epidemic affecting over 6.2 million Americans, with about half having HF with preserved ejection fraction (HFpEF) (1). As the American population continues to age, an increase of $66 \%$ in the age group over 80 years old is predicted by 2030 (2). In addition, the obesity epidemic in the US continues to grow, with 1 in 2 adults projected to be obese by 2030 (3). As a result of the growing aging and obese population, the prevalence of HF is expected to increase across all sex, racial, and ethnic groups (2). HF prevalence is projected to increase $46 \%$ by 2030 to affect over 8 million US adults (2). Importantly, despite the high prevalence of HFpEF, there are currently no FDA approved therapies for health-related outcomes in this clinical syndrome. Thus, HFpEF treatment is one of the greatest unmet needs in cardiovascular medicine.

The diagnosis of HFpEF remains a clinical challenge in cardiology, however, HFpEF is typically characterized by an ejection fraction $>50 \%$ accompanied by diastolic dysfunction, high filling pressures and exercise intolerance (4). The complexity of its diagnosis and the recent proposed algorithms to identify patients with HFpEF have been discussed elsewhere (5).

Within this clinical syndrome, there are distinct phenotypes emerging that could potentially redefine how we design clinical trials and treat HFpEF patients $(6,7)$. The identification of 
the phenotypes of HFpEF would potentially allow to define the most appropriate and tailored therapeutic strategy. This approach has been proposed to finally allow to identify an effective therapy in patients with HFpEF that could be applied in clinical practice.

In regard to the identification of HFpEF phenotypes, obesity has gained attention as a potential one of $\operatorname{HFpEF}(8,9)$, with targeted treatment of obesity hypothesized to improve syndrome-specific health-related outcomes (10). Indeed, HFpEF is now the most common HF associated with obesity $(11,12)$. Specifically, therapies that have been in the past utilized in patients with obesity, but without HFpEF, such as exercise training and caloric restriction-induced weight loss, have recently proven beneficial also in patients with obesity and concomitant HFpEF, at least with regards to exercise capacity and patient reported quality of life (QoL). Long-term effects of such strategies are clearly required to confirm these initial promising findings, as discussed at length in the next paragraphs.

Toward developing effective therapies for these patients, patient reported QoL has emerged as a predominant outcome measure, with an understanding of the physiological contributors to QoL emerging as an important area of investigation. Exercise intolerance is the most commonly reported symptom of HFpEF. The downstream consequences of exercise intolerance include reduced physical activity levels and physical function that have detrimental implications on patient QoL, especially in those individuals with HFpEF who are younger and with concomitant obesity and diabetes mellitus (13). While the manifestations of HFpEF-related exercise intolerance are multifaceted, there has recently been a paradigm shift away from the heart and toward the periphery as the major limitation of exercise capacity. In this respect, abnormalities in body composition may play an important role in exercise intolerance and may be an attractive therapeutic target to improve QoL in these patients. Of note, therapies such as exercise training that have targeted the extra-cardiac peripheral abnormalities (i.e., body composition), have shown beneficial effects in patients with HFpEF, despite little effect on cardiac function (14-17). These results propose that targeting non-cardiac abnormalities could potentially result in improved clinical outcomes in this population, although therapies that may also improve cardiac dysfunction would be desirable.

Sarcopenic obesity (SO), a clinical and functional condition defined by the coexistence of excess adiposity (i.e., obesity) with a decline in muscle mass and related strength and functionality (i.e., sarcopenia), is consistently reported in HFpEF patients and poses as a major limitation to exercise capacity (14). Patients with SO present with reduced exercise capacity characteristic of obesity (18), but also those associated with sarcopenia in the setting of HFpEF (19).

The aim of this review is to provide insights into the contributing physiological mechanisms and outcomes associated with HFpEF-related SO toward improving exercise intolerance and potentially QoL.

\section{SARCOPENIC OBESITY: DEFINITION AND DIAGNOSIS}

SO is commonly defined as the coexistence of sarcopenia and obesity. A recent systematic review of the definitions and diagnosis of sarcopenic obesity reported large heterogeneity in the definition of SO and diagnostic approaches (20). This is likely due to differences in the definitions of sarcopenia and obesity as well as the large range of methodologies employed to assess body composition and strength (20). Despite these limitations, SO is typically diagnosed by the presence of sarcopenia and obesity, each evaluated as separate parameters (21). Future directions in the field are aimed at determining whether SO should be diagnosed based on one composite parameter (20). This is based on the thinking that a synergistic relationship between reduced muscle mass and increased adiposity may result in an independent clinical phenotype (20). A composite diagnostic criterion in this case would have to employ concomitant evaluations of fat mass and fat-free mass (20). As this measure is yet to be determined and established, the separate definitions and diagnoses of sarcopenia and obesity are provided herein.

\section{Sarcopenia}

A recently revised consensus from the European Working Group on Sarcopenia in Older People (EWGSOP) defined sarcopenia as a progressive skeletal muscle disorder that increases the risk of adverse physical outcomes such as falls, fractures, impaired physical function, disability, and mortality (21). While former sarcopenia diagnoses were predominantly based on the reduction of lean mass, the recent consensus prioritizes the presence of reduced muscle strength (dynapenia) and/or physical function in the diagnosis of sarcopenia due to its superiority in predicting adverse events (21). In addition to reductions in functional measures, concurrent declines in muscle mass (myopenia) (22) are also required for a sarcopenia diagnosis (Table 1) (21). With regards to measurements of strength in the diagnosis of sarcopenia, handgrip strength (21), or knee extensor strength (20) by dynamometry are recommended. Alternatively, the $30 \mathrm{~s}$ sit to stand test provides a measure of lower body strength (21). Physical function can be assessed by gait speed, the timed up and go (a measure of speed and agility), the $400 \mathrm{~m}$ walk test or the short physical performance battery (SPPB; gait, balance, and lower body strength) (21). Recommended methods of skeletal muscle mass measurement are bioelectrical impedance analysis (BIA), dual energy X-ray absorptiometry (DXA) or the gold standard magnetic resonance imaging (MRI) $(20,21)$. If these techniques are unavailable, although not optimal, calf circumference can be utilized (21). Readers are referred to the EWGSOP consensus for the sarcopenia diagnostic cut off criteria for the abovementioned methodologies (21).

\section{Obesity}

Obesity is defined as an excessive accumulation and storage of fat in the body that impairs health. Commonly used methodology to diagnose obesity in $\mathrm{SO}$ are body mass index (BMI), waist circumference (WC), and when BIA or DXA are available, 
TABLE 1 | Diagnostic criteria for sarcopenia.

\begin{tabular}{|c|c|c|c|c|c|c|}
\hline & Dynapenia & Myopenia & $\begin{array}{c}\text { Probable } \\
\text { Sarcopenia }\end{array}$ & $\begin{array}{l}\text { Confirmed } \\
\text { sarcopenia }\end{array}$ & $\begin{array}{l}\text { Confirmed } \\
\text { sarcopenia }\end{array}$ & $\begin{array}{c}\text { Severe } \\
\text { sarcopenia }\end{array}$ \\
\hline $\begin{array}{l}\text { Low muscle } \\
\text { strength }\end{array}$ & $\checkmark$ & & $\checkmark$ & $\checkmark$ & $\checkmark$ & $\checkmark$ \\
\hline $\begin{array}{l}\text { Low muscle } \\
\text { quantity }\end{array}$ & & $\checkmark$ & & $\checkmark$ & & $\checkmark$ \\
\hline $\begin{array}{l}\text { Low physical } \\
\text { performance }\end{array}$ & & & & & $\checkmark$ & $\checkmark$ \\
\hline
\end{tabular}

Adapted from (15, 16, 19).

with total body fat mass percentage (20). There has been limited research into which is the most effective measure of obesity in predicting outcomes in the setting of SO. However, a recent study by Khor et al. (23) comparing the use of BMI, WC and fat mass percentage by DXA in the diagnosis of SO revealed that the different methodologies markedly increased the variation in SO prevalence. In this respect, SO prevalence was lowest when BMI was used in comparison to WC and fat mass percentage (23). The findings also showed that WC was most strongly correlated with SO related impairments in physical function (23), supporting previous findings that regional adipose tissue distribution is important in determining functional impairments in SO (24). In this respect, in addition to abdominal adiposity, increased intermuscular fat deposition may be a pathophysiological contributor to dynapenia and impaired physical function that is unique to $\mathrm{SO}(24,25)$.

In the recent years, the role of obesity on atrial function, in addition to ventricles and skeletal muscle has received much attention (4). Of note, left atrial has shown to provide important prognostic information in patients with HFpEF, independent on the presence of obesity; however, when obesity is present, there is a significant increase in right atrial pressure with exercise, specifically, an increased right atrial pressure/peak oxygen consumption has been shown. This suggest that to achieve a given peak oxygen consumption, patients with obesity, and HFpEF reach significantly greater right atrial pressure. This highlights the important role of the left atrial in determining exercise capacity in patients with HFpEF, in which atrial myopathy is often found, and proposed to be a major substrate for the development of atrial fibrillation, which is, in fact, one of the most common comorbidities reported in this population. Interestingly, patients with obesity and HFpEF present an increased epicardial adipose tissue (EAT). The thickness of EAT is significantly associated with greater body mass index (BMI) and right atrial pressure, and is inversely associated with reduced cardiorespiratory fitness (5-8), except for one study, where the association was paradoxically positive, suggesting a beneficial effects of EAT (9). Although the direct effects of EAT are not entirely clear, it has been speculated that EAT may cause a pericardial restraint, potentially exacerbated by mediastinal fat or chest wall issues. In addition, the detrimental indirect effects of EAT that have been proposed are numerous; however, the proinflammatory effects of EAT have been proposed to drive most of the inflammation found in the myocardium itself, as opposed to the non-EAT, which may drive the low-grade systemic inflammation characteristic of obesity and HFpEF (10).

\section{SARCOPENIC OBESITY IN HFpEF}

Both sarcopenia and obesity are well-documented as separate entities in HFpEF patients $(25,26)$. Firstly, aging represents the largest risk factor for cardiovascular disease and HFpEF is the predominant form of HF in the aged population (27). The development of sarcopenia and increased adiposity are elemental sequalae of the aging process (28) and therefore elderly HFpEF patients are already at risk of $\mathrm{SO}$ as a function of age. In addition, HFpEF is typically accompanied by a plethora of comorbidities such as type 2 diabetes mellitus, chronic obstructive pulmonary disease (COPD) and chronic kidney disease (CKD), the pathophysiology of which contribute to "accelerated aging." This not only augments SO in the elderly HFpEF cohort, but it also prematurely predisposes younger individuals with HFpEF to aging related SO phenomena. Secondly, overweight and obesity are highly prevalent in HFpEF affecting $>80 \%$ of patients $(9,29$, $30)$. In this respect, obesity is emerging as a distinct phenotype of $\operatorname{HFpEF}(8,9,13,31)$. Despite a lack of studies in the HFpEF population reporting $\mathrm{SO}$ as a single entity, the high incidence of sarcopenia and obesity as separate parameters is indicative of a widespread SO prevalence in these patients.

\section{CLINICAL CONSEQUENCES OF SARCOPENIC OBESITY IN HFpEF}

\section{Hospitalizations and Survival}

Obesity is a clear risk factor for HF, particularly HFpEF (32). Such effects have been recently proposed to be mediated by the reduced cardiorespiratory fitness (CRF) characteristic of obesity (33). Once HF is diagnosed, however, the effects of increased BMI on clinical outcomes is quite complex, with overweight and obesity being associated with improved clinical outcomes in both HFrEF and HFpEF, at least in observational studies (34). A sub-analysis of the I-PRESERVED trial investigated the association of BMI and adverse outcomes in 4,019 HFpEF patients (29). These analyses showed a U-shaped relationship between BMI and the primary composite endpoint of all-cause mortality and HF-related hospitalizations (29). The adjusted risk of for all-cause mortality and HF-related hospitalizations was significantly greater in patients with a $\mathrm{BMI} \geq 35 \mathrm{~kg} / \mathrm{m}^{2}$ 
and patients with a BMI $<23.5 \mathrm{~kg} / \mathrm{m}^{2}$ compared with BMI categories $23.5-26.4 \mathrm{~kg} / \mathrm{m}^{2}, 26.5-30.9 \mathrm{~kg} / \mathrm{m}^{2}$, and $31-34.9 \mathrm{~kg} / \mathrm{m}^{2}$ (29). A similar analysis of the CHARM study that included 7,599 HF patients, showed similar findings in the cohort of HF patients with preserved ejection fraction (ejection fraction $>40 \%$ ) (30). The difference between these studies was that in the I-PRESERVED trial, patients with a BMI between 16.5 and $30.9 \mathrm{~kg} / \mathrm{m}^{2}$ had the lowest risk of mortality and HF related hospitalization (29). In comparison, in the CHARM trial, the risk was lowest in obese patients with a BMI between 30 and $34.9 \mathrm{~kg} / \mathrm{m}^{2}$ (30). This finding has been replicated in other large epidemiological studies of HF, introducing an "obesity paradox" whereby obesity appears to have a protective effect in HF (35-37). Whether the obesity paradox exists in the HFpEF cohort of HF is keenly debated and warrants further investigation $(9,35,38)$. Nonetheless, a consistent finding is that underweight patients with HFpEF, and those who lose weight over time in the absence of a structured lifestyle intervention have an increased risk of allcause mortality and HF hospitalization rates $(29,30,39)$. This demonstrates the detrimental effects of unintentional weight loss, likely resulting in reduced lean mass, on clinical outcome in these patients. Toward gaining a clearer understanding of the obesity paradox, future studies in HFpEF that investigate the effects of concomitant sarcopenia and obesity on clinical outcomes are urgently needed. In such studies, the inclusion of CRF, muscle strength and impaired physical function alongside body composition measures would provide a more holistic insight toward identifying specific treatment targets to improve clinical outcomes in this complex syndrome $(35,38)$.

\section{Cardiovascular Outcomes}

Whether obesity is a driver of cardiac dysfunction in HFpEF or whether it coexists alongside HFpEF, influencing the presentation of the syndrome remains controversial $(8,10,40)$. A study by Obakata et al. compared HFpEF patients with obesity with HFpEF patients without obesity and non-obese healthy controls. Their findings showed that HFpEF patients with obesity had significantly increased estimated plasma volume, abnormal right, and left heart cardiac structure and increased ventricular filling pressures during exercise (8). This data points toward a central role of obesity in the development and progression of HFpEF (8). The study, however, did not include a group of obese individuals without HF, making it impossible to differentiate whether the effects reported were specifically resulting from the HFpEF obesity phenotype, or whether individuals with a obesity would have reported similar findings (10). Alternatively, Carbone et al. reported no relationship between obesity and measures of systolic and diastolic cardiac function assessed by echocardiography at rest and at peak exercise (18). Additionally, although weight loss following caloric restriction in HFpEF patients and concomitant obesity, despite improved CRF, it has no clinically significant effects on diastolic function (14).

There is currently little directly linking sarcopenia to cardiac abnormalities in HFpEF. It is speculated that inflammation and endocrine changes related to myopenia, in addition to a sedentary lifestyle, secondary to sarcopenia, provide a pathophysiological environment conducive to cardiac diastolic dysfunction $(41,42)$.
Likewise, the role of $\mathrm{SO}$ in driving cardiac abnormalities in HFpEF remains undetermined. In the SICA-HF study of $117 \mathrm{HF}$ patients, the quartile of patients with the worst diastolic function and estimated filling pressures $\left(\mathrm{E} / \mathrm{e}^{\prime}>15\right)$ reported the lowest levels of appendicular lean mass (i.e., lean mass of extremities) and muscle strength (43). A recent retrospective analysis of 733 Koreans investigated the role of SO on cardiac parameters in individuals without overt cardiovascular disease (42). The analyses compared individuals with obesity and without obesity, with and without concurrent sarcopenia (42). When controlling for confounding variables, those with SO had the highest risk for diastolic dysfunction compared to those that had only sarcopenia or obesity (42). This suggests a potential role of SO in cardiac dysfunction which appears to be driven by synergistic crosstalk between reduced lean mass and excess adiposity, however, these data need to be followed up in studies of HFpEF patients.

\section{Quality of Life}

Due to the discouraging lack of positive clinical trials to improve outcome in HFpEF, there has been a shift toward strategies that focus on improving patient QoL as the primary endpoint. A recent amalgamation of leading $\mathrm{HFpEF}$ clinical trial data from NEAT-HFpEF, INDIE-HFpEF, and RELAX by Reddy et al. assessed relationships between HFpEF severity variables and QoL (13). With participants split into tertiles based upon QoL, the HFpEF group with worst QoL had the highest BMI and the greatest prevalence of class 2 obesity (13). After adjusting for age, sex, and BMI, QoL was worst in those with the lowest physical activity and physical function measures (11). Furthermore, the SICA-HF study demonstrates a positive correlation between appendicular lean mass, muscle strength and QoL (43). These data hold promise for $\mathrm{SO}$ as a potential therapeutic target to improve patient reported QoL.

\section{Exercise Intolerance}

As mentioned previously, exercise tolerance is the most common reported symptom of HFpEF and holds promise as a therapeutic target to improve patient reported QoL in this patient population (44). In these patients, obesity is consistently linked with a reduction in cardiorespiratory fitness, assessed as maximal oxygen uptake $\left(\mathrm{VO}_{2}\right.$ peak), the gold standard measurement of exercise capacity $(8,31)$. In this respect, the regional distribution of adipose tissue plays an integral role in HFpEF related exercise intolerance (24). Intra-Abdominal fat is the strongest independent predictor of $\mathrm{VO}_{2}$ peak, with abdominal subcutaneous fat, thigh subcutaneous fat and thigh intramuscular fat: skeletal muscle ratio all negatively associated with $\mathrm{VO}_{2}$ peak (24). The underlying mechanisms of obesityrelated reduction in exercise capacity in HFpEF are not yet fully elucidated. As diastolic dysfunction has previously been reported as a central limitation to exercise capacity (45), it is reasonable to infer that the obesity driven changes in cardiac function may partly explain these reductions. However, a paradigm shift toward the periphery implicates skeletal muscle abnormalities that are synonymous with sarcopenia as the predominant limitation of exercise capacity in these patients (46). In this regard, aberrant skeletal muscle structure and 
function reported in HFpEF patients hamper oxygen extraction and utilization during exercise with deleterious consequences on exercise capacity $(46,47)$. Readers are referred to in-depth reviews detailing skeletal muscle dysfunctions and their role in exercise intolerance in $\operatorname{HF}(25,48)$. In support of this paradigm, appendicular muscle mass, and skeletal muscle mass are strongly associated with $\mathrm{VO}_{2}$ peak and physical function in HFpEF, even when adjusting for other contributing factors to exercise intolerance such as iron deficiency, pulmonary function, and New York Heart Association (NYHA) class (43). The effect of coexisting sarcopenia and obesity on HFpEF related exercise intolerance is yet to be delineated. However, an elegant study by Zamani et al. has recently demonstrated that adiposity is inversely associated with local skeletal muscle oxygen consumption in HFpEF patients (47). In addition, in the previously mentioned retrospective analysis of "healthy" Koreans without overt cardiovascular disease, individuals with $\mathrm{SO}$ reported significantly lower $\mathrm{VO}_{2}$ peak compared with those who only had sarcopenia or obesity (42). This supports the idea of synergistic cross-talk between adipose tissue and skeletal muscle that is deleterious to functional capacity. Future investigations into the effects of adipose tissue on skeletal muscle in the setting of HFpEF are warranted.

In addition, patients with obesity and HFpEF present with greater plasma volume and increased filling pressures, which have not been consistently identified in patients without HFpEF (1). Moreover, patients with obesity present a greater septal flattening, likely resulting from a greater external constraints on the heart caused by obesity (1). In addition, when obesity and HFpEF coexist, despite similar metabolic work, the measured external work reported is significantly lower (1). Finally, patients with the obesity/HFpEF phenotype seem to respond less to decongestive therapies (2).

\section{PATHOPHYSIOLOGY OF SARCOPENIC OBESITY IN HFpEF}

An overview of the multifaceted pathophysiological mechanisms that contribute to HFpEF related SO are highlighted in Figure 1.

\section{Inflammation}

There is abundant evidence for inflammation in patients with HFpEF with circulating biomarkers of inflammation consistently reported to be substantially high in these patients $(49,50)$. Systemic inflammation is high in these patients due to volume overload that increases levels of angiotensin II, triggering a subsequent immune cascade; systemic microvascular inflammation; and the presence of co-morbidities such as hypertension, diabetes, anemia, chronic kidney disease, ischemic heart disease, stroke, and cancer are all marked by chronic systemic inflammation (49, 50). A chronic inflammatory environment has been consistently implicated in the pathogenesis of sarcopenia by impairing protein turnover and synthesis and increasing skeletal muscle catabolism (51). Of particular relevance to SO, the increased adipose tissue provides an additional source of inflammation

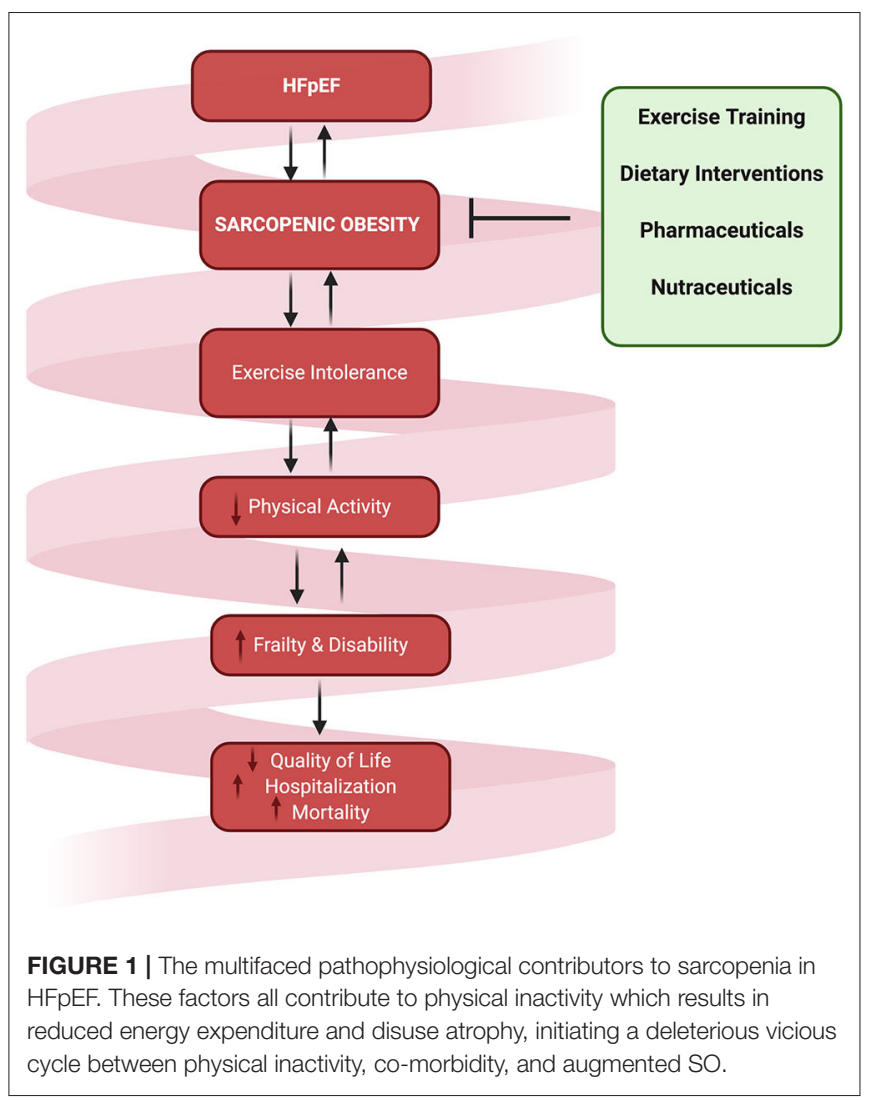

(52) that directly induces skeletal muscle atrophy $(53,54)$. Additionally, monocyte chemoattractant protein (MCP-1), a key chemokine in inflammatory cell trafficking, has been shown to be high in cardiac cachexia leading to increased monocyte and macrophage trafficking to adipose tissue resulting in an exacerbation of inflammatory cytokine secretion $(55,56)$.

\section{Oxidative Stress}

Circulating markers of oxidative stress are increased in the setting of HFpEF and SO (57). The role of oxidative stress in HFpEF related obesity is not yet fully understood however, in individuals with $\mathrm{SO}$, increased oxidative stress has been shown to be correlated with cardiovascular disease risk (57). Increased oxidative stress contributes to endothelial dysfunction by reducing the production and bioavailability of nitric oxide (NO) resulting in microvascular dysfunction which is a hallmark of $\operatorname{HFpEF}(58,59)$. Impaired endothelial function can hamper blood flow and oxygen diffusion to the working muscle, thus potentially playing a role in exercise intolerance and the development of sarcopenia $(25,46)$. The sources of oxidative stress in HFpEF are multifaceted and have not yet been fully elucidated. Certainly, inflammation is characteristic of this HFpEF that is augmented by $\mathrm{SO}$ is a likely major contributor to increased levels of oxidative stress $(60,61)$. Cardiac ischemia and tissue hypoxia have also been implicated to play a role in HFpEF related oxidative stress $(61,62)$. In this respect, hypoxia related increases in uric acid have been reported in these patients (62). Therefore, xanthine 
oxidase, the ROS generating enzyme the catalyzes the oxidation of xanthine to uric acid could be a potential source of oxidative stress in HFpEF. Mitochondrial dysfunction that is consistently reported in $\mathrm{HFpEF}$ is an additional source of oxidative stress (63). Uncoupled endothelial nitric oxide synthesis (eNOS) due to reduced levels of the NO precursor L-Arginine and increased levels of the L-Arginine competitor asymmetric dimethylarginine is also a likely source of oxidative stress in these patients (62). Whether an activated renin angiotensin aldosterone system (RAAS) leading to increased levels of Angiotensin II is a source of oxidative stress in these patients remains controversial $(64,65)$. The discouraging lack of efficacy of RAAS targeted therapies in this syndrome supports some evidence that RAAS is not a major contributor to oxidative stress (65). As broadlevel antioxidant therapies have generally not been successful at improving cardiovascular end-points (66), it is important that future research in HFpEF identifies the specific sources of excessive reactive species generation in order to develop targeted strategies to reduce oxidative stress.

\section{Endocrine Abnormalities}

Multihormone hormone deficiency (MHDS) has been cited as a cause and consequence of $\operatorname{HF}(67,68)$. Although relatively unexplored in the HFpEF cohort of HF, many of these patients present with one or more components of MHDS, these being an aberrant insulin like growth factor/growth hormone (IGF$1 / \mathrm{GH}$ ) axis, abnormal levels of thyroid hormones, and androgens and insulin resistance (67-69). These hormone abnormalities are implicated in skeletal muscle catabolism and anabolic deficiency with downstream consequences on functional capacity (68).

Chronic low grade inflammation in obesity that may contribute to muscle wasting is regulated in part by adiponectin, leptin, and insulin controlling various inflammatory and anti-inflammatory processes (70-74). In obesity, homeostatic model assessment of insulin resistance (HOMA-IR) values are commonly increased $(70,71)$ and leptin is elevated, too $(74)$. Adiponectin has been shown to be low and negatively correlated with BMI, plasma insulin, tumor necrosis factor alpha (TNF- $\alpha$ ), and interleukin 6 (IL-6) (70). Heart failure with reduced ejection fraction (HFrEF) is known to have an uncommon adiponectin cascade compared to what is seen in obesity related conditions though it is unknown whether this also occurs in HFpEF due to limited research. One study that sought to evaluate this cascade in the two HF subtypes determined that in HFpEF and HFrEF leptin levels were high compared to matched healthy controls (72). Adiponectin was the same across groups until adjusted for age and BMI where it was higher in HF than controls (72). Adiponectin resistance has been determined to be present in HFpEF through higher adiponectin mRNA expression despite similar adiponectin secretion compared to healthy controls (73). Similar to obesity, adiponectin has a negative correlation to BMI in HF whilst leptin and insulin correlated positively with BMI (72).

\section{Mitochondrial Dysfunction}

Skeletal muscle mitochondrial dysfunction is sentinel to the pathogenesis of sarcopenia through its dysregulation of myocyte function and viability (75). Impairments in mitochondrial function occur in parallel with decrements in strength throughout the spectrum of sarcopenia (76). In aging models of sarcopenia in mice, skeletal muscle mitochondrial dysfunction appears to be precursor to the development of sarcopenia as abnormalities are observed prior to declines in strength and muscle dystrophy (76). Potential contributors to HFpEF related mitochondrial dysfunction are thought to be chronic adrenergic activity, inflammation and oxidative stress (25, 77-81).

Additionally, skeletal muscle mitochondrial dysfunction results in a disruption in metabolism due to a reduced capacity for lipid oxidation. In the presence of increased circulating free fatty acids and triglycerides, incomplete fatty acid oxidation, and insulin resistance, an impairment in mitochondrial oxidative capacity could result in substrate overload and the previously described accumulation of lipid intermediates in the skeletal muscle (82). As previously mentioned, this accumulation of intramuscular fat is associated with $\mathrm{SO}$ and is positively associated with functional capacity in HFpEF (24).

\section{Iron Deficiency}

Iron deficiency (ID) is highly prevalent in HFpEF and is more prominent in patients with more severe diastolic dysfunction. HFpEF related ID is thought to be a result of inflammation mediated reductions hepcidin, the principal regulator of iron absorption and tissue distribution (83-85). In addition, gastrointestinal irregularities that reduce gastric emptying and intestinal iron absorption are evident in these patients (83, 84, 86). In HFpEF patients, meta-analyses have shown ID to be correlated with reductions in exercise capacity, physical functional and worse QoL $(83,87)$. ID is hypothesized to play a role in lean mass abnormalities, sarcopenia and the consequential reductions in functional capacity via impaired cardiac and skeletal mitochondrial function as these organelles require iron for optimal oxidative phosphorylation enzyme function $(83,88)$.

\section{Disuse}

Individuals with HFpEF are highly sedentary and therefore the resultant reduction in energy expenditure combined with disuse atrophy may contribute to SO in these patients (46, 89, 90). Sarcopenia is caused for the most part by physical inactivity. Patients with obesity that, however, remain physically active and maintain a preserved cardiorespiratory fitness, may not necessarily develop sarcopenia, possibly resulting in more favorable prognosis. Interestingly, a recent analysis of Korean individuals suggested that sarcopenia may also directly affect cardiac diastolic function, therefore impairing exercise capacity not only by affecting the peripheral determinants of cardiorespiratory fitness, but possibly by also affecting cardiac function (3).

Certainly, the co-morbidities and symptoms associated with HFpEF may contribute to exertional fatigue and the reduction in physical activity, thus augmenting a vicious cycle of disuse atrophy and increased adiposity (Figure 2). Although the role of physical inactivity in HFpEF related SO has not yet been clearly established, increasing physical activity levels through exercise 


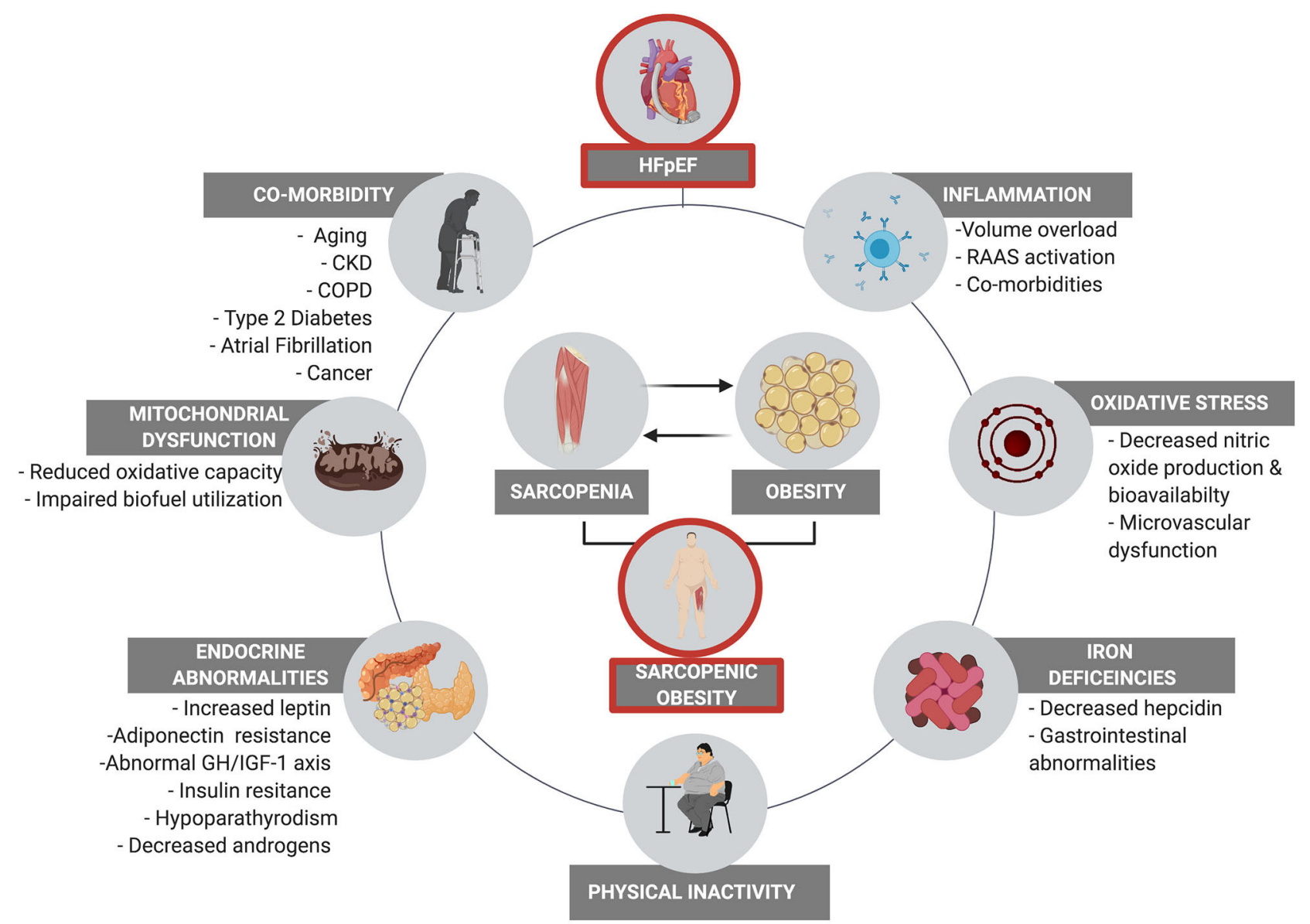

FIGURE 2 | The downward spiral of SO and physical inactivity that culminates in reduced quality of life, increased hospitalization, and mortality. Interventions targeting $\mathrm{SO}$ in HFpEF are urgently warranted to reverse the associated detrimental downstream consequences.

training is one of the only therapies that has proven efficacious for improving exercise capacity $(16,91-93)$. The predominant mechanisms of these improvements in exercise tolerance are suggested to be mediated for the most part through beneficial skeletal muscle adaptations $(15,24,91,94)$.

\section{CURRENT AND PROSPECTIVE INTERVENTIONS FOR SARCOPENIC OBESITY IN HFpEF}

\section{Exercise Training}

Despite relatively few randomized controlled trials that investigated exercise training in HFpEF, exercise training has consistently been shown to be efficacious at improving exercise capacity and QoL in this patient population (15, 91, 95-99). The implemented exercise interventions are predominantly aerobic in nature with exercise prescribed initially at a light-moderate intensity and gradually progressed to a moderate-vigorous intensity $(15,91,95,96,98)$. High intensity interval training appears to be superior to moderate (100) continuous training at eliciting improvements in exercise capacity $(91,94,97)$.
As meta-analyses reveal limited changes in cardiac function following exercise training in HFpEF (15), the beneficial effects of training on exercise tolerance appear to be driven by peripheral improvements in skeletal muscle health and function (94). With reference to SO, there are currently no known trials in HFpEF that have investigated the effects of exercise on body composition as the primary outcome. In this respect, high intensity progressive resistance training is deemed the most effective mode of exercise to elicit an anabolic response and has shown positive results in other sarcopenic and cachexic populations (101-104). Such investigations are warranted in HFpEF patients with SO.

\section{Dietary Interventions and Bariatric Surgery}

Effective nutrition interventions are urgently needed in the overall $\mathrm{HF}$ population and are especially lacking in HFpEF (105). To date, no nutrition interventions have specifically been performed in patients with comorbid HFpEF and SO. Healthy dietary patterns, specifically the Mediterranean diet (MedDiet) may be associated with a lower incidence of sarcopenia (106108). Recently, a prospective study in Spain assessed adherence 
to the MedDiet in 991 patients diagnosed in the emergency department with acute HF on a primary endpoint of allcause mortality. While the primary endpoint was not met, the secondary endpoint of rehospitalization was significant lower in those adhering to a MedDiet ( $\mathrm{HR}=0.76,95 \%$ CI $0.62-0.93$ ) $(105,109)$. The MedDiet is rich in fruits, vegetables, whole grains, legumes, and particularly unsaturated fatty acids (UFA), which have been associated with more favorable body composition, such as greater fat-free mass (FFM) and FFM to fat mass (FM) ratio as well as improved cardiac diastolic function and greater $\mathrm{VO}_{2}$ peak in HFpEF patients (110). Of note, in the UFA-Preserved pilot study, a diet supplemented with foods rich in UFA such as extra-virgin olive oil, canola oil, and mixed tree nuts was associated with increased plasma levels of UFA in patients with obesity and HFpEF, showing that it is a feasible intervention in this population and associated with favorable changes in CRF (111). A larger ongoing randomized crossover trial, the UFAPreserved 2 (NCT03966755), is designed to evaluate the effects of daily UFA supplementation through dietary sources on a primary outcome of change in dietary UFA and plasma UFA biomarkers, while also assessing changes in body composition, cardiac function and exercise capacity. Another healthy dietary pattern, the Dietary Approaches to Stop Hypertension (DASH) diet, is effective in treating hypertension and has also been shown to reduce clinic and 24-h systolic (155-138 and 130-123 mm Hg, respectively), and diastolic (79-72, and 67-62) blood pressure, arterial stiffness measured by carotid-femoral pulse wave velocity (12.4 to $11.0 \mathrm{~m} / \mathrm{s})$, improve diastolic left ventricular relaxation (difference in $\mathrm{c}=-4.2 \pm 6.2$ ) and chamber stiffness (difference in $k=-81 \pm 99 \mathrm{~s}-1$ ) and ventricular-arterial coupling (difference in $\mathrm{Ees}: \mathrm{Ea}=-0.2 \pm 0.3)$ when combined with sodium restriction in HFpEF patients $(80,112)$. Recently, the GOURMET-HF trial assigned 66 patients with HFrEF and HFpEF discharged from the hospital after admission for HF exacerbation 1:1 to either a sodium restricted ( $<1,500 \mathrm{mg} /$ day) DASH diet, which was home delivered, or usual care for 4 weeks. While the study did not meet the primary outcome of between group change in Kansas City Cardiomyopathy Questionnaire summary score, but participants assigned to the DASH diet demonstrated a favorable trend in rehospitalization at 30 days (11 vs. 27\%) (113).

Protein supplementation, coupled with resistance exercise, may help increase appendicular muscle mass while reducing total and abdominal obesity as well as inflammatory biomarkers in women with sarcopenic obesity (114). While the most recent Heart Failure Society of America Scientific Statement recommended a protein intake of at least $1.1 \mathrm{~g}$ per kilogram per day (115), trials of protein and amino acid supplementation in patients with sarcopenia and HF have primarily performed in HFrEF patients and have yielded mixed results $(116,117)$.

Finally, the SECRET trial assigned 100 patients with obesity and HFpEF to a $2 \times 2$ factorial trial of exercise training, caloric restriction, both caloric restriction, and exercise training or control. The main effect of caloric restriction was weight loss $(-7 \mathrm{~kg}, 95 \% \mathrm{CI}-5-9)$ which resulted in an increase in $\mathrm{VO}_{2}$ peak $(+1.3,95 \%$ CI $0.2-2.3)$, as well as a reduction in FM $(-5 \mathrm{~kg}$, $95 \% \mathrm{CI}-4-6, p<0.001)$ and percent body FM $(-2 \%, 95 \%$ $\mathrm{CI}-1-3)$ (14). However, lean mass ( $-2 \mathrm{~kg}$, 95\% CI-1-3) was also reduced in these patients with caloric restriction alone, an important consideration in patients with SO (14). Notably, main effect of exercise revealed no loss of lean mass, suggesting that concomitant exercise training may help to preserve lean mass with caloric restriction (14). The currently enrolling SECRETII trial (NCT02636439) is testing caloric restriction combined with aerobic exercise training alone vs. combined with resistance exercise training in patients with HFpEF.

In addition to weight loss induced by caloric restriction, there is a growing interest in understanding the role of bariatric surgery in this population. In HF, observational studies suggest clinical benefits of this intervention (11), however, randomized controlled trial are needed to confirm those findings. First, bariatric surgery induces significant weight loss to a greater degree than lifestyle intervention alone. This effect alone would allow to improve exercise capacity and quality of life $(12,13)$. The other potential effects of bariatric surgery are numerous, including the ability to reduce epicardial adipose tissue, which would be beneficial based on the above discussion. Moreover, bariatric surgery has been associated with reduced markers of systemic inflammation as well as localized adipose tissue inflammation (11), potential targets in patients with obesity and HFpEF.

Considering the lack of available therapies in HFpEF and prevalence of SO in this population, there is an urgent need to identify whether dietary pattern, protein supplementation or caloric restriction as well as bariatric surgery are able to improve outcomes in this population.

\section{Pharmaceutical and Nutraceutical}

The discouraging lack of clinical outcomes pertaining to pharmacological therapies in HFpEF has provided a major challenge to cardiologists managing this syndrome. Despite a lack of beneficial outcomes pertaining to hospitalization and mortality in these patients, pharmaceutical therapies have resulted in clinical meaningful improvements in exercise capacity and QoL (96). In this respect, vasodilators, and chronotropic therapies appear to be efficacious, whist RAAS inhibitors have no effect (96). The DHART Trials investigating the effects of IL-1 blockade in HFpEF patients have shown promising improvements in exercise capacity and quality of life (77, $118,119)$. In addition, inorganic and organic nitrates hold promise for improving exercise capacity in these patients (120122). As with exercise training, there are no pharmacological strategies that have specifically targeted SO in human subject trials of HFpEF. As we continue to understand more about the pathophysiology of HFpEF related SO, future pharmacological or nutraceutical therapies targeting these aberrant molecular pathways in combination with exercise training may be a powerful approach to combat SO.

\section{CONCLUSIONS}

In summary, $\mathrm{SO}$ is prevalent in patients with $\mathrm{HFpEF}$ and has noteworthy adverse consequences on end point outcomes, health related outcomes and patient reported QoL. Although the multifaceted pathophysiology of HFpEF related SO is not yet fully understood, inflammation, oxidative stress, hormonal imbalances, iron deficiency, and sedentary lifestyle appear 
to contribute to this condition. In addition, the plethora of comorbidities that accompany this syndrome further exacerbate the physiological milieu implicated in SO. Moreover, being obesity a major risk factors for several comorbidities, including coronary heart disease, future research should try to assess the diverse effects of obesity and HFpEF on clinical outcomes.

Whilst exercise training as well as some dietary and pharmaceutical approaches appear to be efficacious at improving exercise capacity and QoL, there is a lack of interventional trials that specifically target $\mathrm{SO}$ in these patients. There is therefore an urgent need for lifestyle, pharmaceutical or nutraceutical approaches to address SO toward improving clinical and disease modifying outcomes in HFpEF.

\section{REFERENCES}

1. Benjamin EJ, Muntner P, Alonso A, Bittencourt MS, Callaway CW, Carson AP, et al. Heart disease and stroke statistics-2019 update: a report from the American heart association. Circulation. (2019) 139:e56528. doi: 10.1161/CIR.0000000000000659

2. Heidenreich PA, Albert NM, Allen LA, Bluemke DA, Butler J, Fonarow GC, et al. Forecasting the impact of heart failure in the United States: a policy statement from the American heart association. Circ Heart Fail. (2013) 6:606-19. doi: 10.1161/HHF.0b013e318291329a

3. Ward ZJ, Bleich SN, Cradock AL, Barrett JL, Giles CM, Flax C, et al. Projected U.S. state-level prevalence of adult obesity and severe obesity. N Engl J Med. (2019) 381:2440-50. doi: 10.1056/NEJMsal 909301

4. Pieske B, Tschöpe C, de Boer RA, Fraser AG, Anker SD, Donal E, et al. How to diagnose heart failure with preserved ejection fraction: the HFA-PEFF diagnostic algorithm: a consensus recommendation from the heart failure association (HFA) of the European society of cardiology (ESC). Eur J Heart Fail. (2020) 22:391-412. doi: 10.1002/ejhf.1741

5. Del Buono MG, Iannaccone G, Scacciavillani R, Carbone S, Camilli M, Niccoli G, et al. Heart failure with preserved ejection fraction diagnosis and treatment: an updated review of the evidence. Prog Cardiovasc Dis. (in press). doi: 10.1016/j.pcad.2020.04.011

6. Shah SJ, Kitzman DW, Borlaug BA, van Heerebeek L, Zile MR, Kass $\mathrm{DA}$, et al. Phenotype-specific treatment of heart failure with preserved ejection fraction: a multiorgan roadmap. Circulation. (2016) 134:7390. doi: 10.1161/CIRCULATIONAHA.116.021884

7. Silverman DN, Shah SJ. Treatment of heart failure with preserved ejection fraction (HFpEF): the phenotype-guided approach. Curr Treat Options Cardiovasc Med. (2019) 21:20. doi: 10.1007/s11936-019-0709-4

8. Obokata M, Reddy YNV, Pislaru SV, Melenovsky V, Borlaug BA. Evidence supporting the existence of a distinct obese phenotype of heart failure with preserved ejection fraction. Circulation. (2017) 136:619. doi: 10.1161/CIRCULATIONAHA.116.026807

9. Oh A, Okazaki R, Sam F, Valero-Munoz M. Heart failure with preserved ejection fraction and adipose tissue: a story of two tales. Front Cardiovasc Med. (2019) 6:110. doi: 10.3389/fcvm.2019.00110

10. Carbone S, Canada JM, Abbate A. Letter by carbone et al. regarding article, "evidence supporting the existence of a distinct obese phenotype of heart failure with preserved ejection fraction”. Circulation. 137:4145. doi: 10.1161/CIRCULATIONAHA.117.030432

11. Reddy YNV, Borlaug BA. Heart failure with preserved ejection fraction: where do we stand? Mayo Clin Proc. (2020) 95:62931. doi: 10.1016/j.mayocp.2020.02.015

12. Pfeffer MA, Shah AM, Borlaug BA. Heart failure with preserved ejection fraction in perspective. Circ Res. (2019) 124:1598617. doi: 10.1161/CIRCRESAHA.119.313572

\section{AUTHOR CONTRIBUTIONS}

$\mathrm{DK}, \mathrm{NB}, \mathrm{HB}$, and SC contributed to the content of the manuscript. $\mathrm{DK}, \mathrm{NB}, \mathrm{HB}$, and SC edited manuscript drafts. $\mathrm{DK}, \mathrm{NB}, \mathrm{HB}$, and SC approved the final version of the manuscript. All authors agree to be accountable for the content of the manuscript.

\section{FUNDING}

DK is supported by a Career Development Award 19CDA34740002 from the American Heart Association. SC is supported by a Career Development Award 19CDA34660318 from the American Heart Association.

13. Reddy YNV, Rikhi A, Obokata M, Shah SJ, Lewis GD, AbouEzzedine OF, et al. Quality of life in heart failure with preserved ejection fraction: importance of obesity, functional capacity, and physical inactivity. Eur J Heart Fail. (2020) 22:1009-18. doi: 10.1002/ejhf.1788

14. Kitzman DW, Brubaker P, Morgan T, Haykowsky M, Hundley G, Kraus WE, et al. Effect of caloric restriction or aerobic exercise training on peak oxygen consumption and quality of life in obese older patients with heart failure with preserved ejection fraction: a randomized clinical trial. JAMA. (2016) 315:36-46. doi: 10.1001/jama.2015.17346

15. Pandey A, Parashar A, Kumbhani D, Agarwal S, Garg J, Kitzman D, et al. Exercise training in patients with heart failure and preserved ejection fraction: meta-analysis of randomized control trials. Circ Heart Fail. (2015) 8:33-40. doi: 10.1161/CIRCHEARTFAILURE.114.001615

16. Lavie CJ, Ozemek C, Carbone S, Katzmarzyk PT, Blair SN. Sedentary behavior, exercise, and cardiovascular health. Circ Res. (2019) 124:799815. doi: 10.1161/CIRCRESAHA.118.312669

17. Carbone S, Del Buono MG, Ozemek C, Lavie CJ. Obesity, risk of diabetes and role of physical activity, exercise training and cardiorespiratory fitness. Prog Cardiovasc Dis. (2019) 62:327-33. doi: 10.1016/j.pcad.2019.08.004

18. Carbone S, Canada JM, Buckley LF, Trankle CR, Dixon DL, Buzzetti $\mathrm{R}$, et al. Obesity contributes to exercise intolerance in heart failure with preserved ejection fraction. J Am Coll Cardiol. (2016) 68:24878. doi: 10.1016/j.jacc.2016.08.072

19. Emami A, Saitoh M, Valentova M, Sandek A, Evertz R, Ebner N, et al. Comparison of sarcopenia and cachexia in men with chronic heart failure: results from the studies investigating co-morbidities aggravating heart failure (SICA-HF). Eur J Heart Fail. (2018) 20:1580-7. doi: 10.1002/ejhf.1304

20. Donini LM, Busetto L, Bauer JM, Bischoff S, Boirie Y, Cederholm $\mathrm{T}$, et al. Critical appraisal of definitions and diagnostic criteria for sarcopenic obesity based on a systematic review. Clin Nutr. (2019) 39:236888. doi: 10.1016/j.clnu.2019.11.024

21. Cruz-Jentoft AJ, Bahat G, Bauer J, Boirie Y, Bruyere O, Cederholm T, et al. Sarcopenia: revised European consensus on definition and diagnosis. Age Ageing. (2019) 48:16-31. doi: 10.1093/ageing/afy169

22. Fearon K, Evans WJ, Anker SD. Myopenia-a new universal term for muscle wasting. J Cachexia Sarcopenia Muscle. (2011) 2:1-3. doi: 10.1007/s13539-011-0025-7

23. Khor EQ, Lim JP, Tay L, Yeo A, Yew S, Ding YY, et al. Obesity definitions in sarcopenic obesity: differences in prevalence, agreement and association with muscle function. J Frailty Aging. (2020) 9:37-43. doi: 10.14283/jfa.2019.28

24. Haykowsky MJ, Nicklas BJ, Brubaker PH, Hundley WG, Brinkley TE, Upadhya B, et al. Regional adipose distribution and its relationship to exercise intolerance in older obese patients who have heart failure with preserved ejection fraction. JACC Heart Fail. (2018) 6:640-9. doi: 10.1016/j.jchf.2018.06.002

25. Carbone S, Billingsley HE, Rodriguez-Miguelez P, Kirkman DL, Garten $\mathrm{R}$, Franco RL, et al. Lean mass abnormalities in heart failure: the role of 
sarcopenia, sarcopenic obesity, and cachexia. Curr Probl Cardiol. (2019) 28:100417. doi: 10.1016/j.cpcardiol.2019.03.006

26. Carbone S, Lavie CJ, Elagizi A, Arena R, Ventura HO. The impact of obesity in heart failure. Heart Fail Clin. (2020) 16:71-80. doi: 10.1016/j.hfc.2019.08.008

27. Owan TE, Hodge DO, Herges RM, Jacobsen SJ, Roger VL, Redfield MM. Trends in prevalence and outcome of heart failure with preserved ejection fraction. N Engl J Med. (2006) 355:251-9. doi: 10.1056/NEJMoa052256

28. Delmonico MJ, Harris TB, Visser M, Park SW, Conroy MB, Velasquez-Mieyer P, et al. Longitudinal study of muscle strength, quality, and adipose tissue infiltration. Am J Clin Nutr. (2009) 90:1579-85. doi: 10.3945/ajcn.2009.28047

29. Haass M, Kitzman DW, Anand IS, Miller A, Zile MR, Massie BM, et al. Body mass index and adverse cardiovascular outcomes in heart failure patients with preserved ejection fraction: results from the irbesartan in heart failure with preserved ejection fraction (I-PRESERVE) trial. Circ Heart Fail. (2011) 4:324-31. doi: 10.1161/CIRCHEARTFAILURE.110.959890

30. Kenchaiah S, Pocock SJ, Wang D, Finn PV, Zornoff LA, Skali H, et al. Body mass index and prognosis in patients with chronic heart failure: insights from the candesartan in heart failure: assessment of reduction in mortality and morbidity (CHARM) program. Circulation. (2007) 116:62736. doi: 10.1161/CIRCULATIONAHA.106.679779

31. Carbone S, Popovic D, Lavie CJ, Arena R. Obesity, body composition and cardiorespiratory fitness in heart failure with preserved ejection fraction. Future Cardiol. (2017) 13:451-63. doi: 10.2217/fca-2017-0023

32. Pandey A, LaMonte M, Klein L, Ayers C, Psaty BM, Eaton CB, et al. Relationship between physical activity, body mass index, and risk of heart failure. J Am Coll Cardiol. (2017) 69:1129-42. doi: 10.1016/j.jacc.2016.11.081

33. Kokkinos P, Faselis C, Franklin B, Lavie CJ, Sidossis L, Moore H, et al. Cardiorespiratory fitness, body mass index and heart failure incidence. Eur $\mathrm{J}$ Heart Fail. (2019) 21:436-44. doi: 10.1002/ejhf.1433

34. Padwal R, McAlister FA, McMurray JJ, Cowie MR, Rich M, Pocock S, et al. The obesity paradox in heart failure patients with preserved versus reduced ejection fraction: a meta-analysis of individual patient data. Int J Obes. (2014) 38:1110-4. doi: 10.1038/ijo.2013.203

35. Carbone S, Canada JM, Billingsley HE, Siddiqui MS, Elagizi A, Lavie CJ. Obesity paradox in cardiovascular disease: where do we stand? Vasc Health Risk Manag. (2019) 15:89-100. doi: 10.2147/VHRM.S168946

36. Carbone S, Elagizi A, Lavie CJ. The obesity paradox in cardiovascular diseases: current evidence and future perspectives. J Clin Exerc Physiol. (2018) 8:30-53. doi: 10.31189/2165-6193-8.1.30

37. Carbone S, Lavie CJ, Arena R. Obesity and heart failure: focus on the obesity paradox. Mayo Clinic Proc. (2017) 92:266-79. doi: 10.1016/j.mayocp.2016.11.001

38. Carbone S, Lavie CJ. Disparate effects of obesity on survival and hospitalizations in heart failure with preserved ejection fraction. Int $\mathrm{J}$ Obes. (2020) 144:1543-45. doi: 10.1038/s41366-020-0579-6

39. Pocock SJ, McMurray JJ, Dobson J, Yusuf S, Granger CB, Michelson EL, et al. Weight loss and mortality risk in patients with chronic heart failure in the candesartan in heart failure: assessment of reduction in mortality and morbidity (CHARM) programme. Eur Heart J. (2008) 29:264150. doi: 10.1093/eurheartj/ehn420

40. Obokata M, Borlaug BA. Response by obokata and borlaug to letters regarding article, "evidence supporting the existence of a distinct obese phenotype of heart failure with preserved ejection fraction". Circulation. 137:416-17. doi: 10.1161/CIRCULATIONAHA.117.031394

41. Kinugasa $\mathrm{Y}$, Yamamoto $\mathrm{K}$. The challenge of frailty and sarcopenia in heart failure with preserved ejection fraction. Heart. (2017) 103:1849. doi: 10.1136/heartjnl-2016-309995

42. Jung MH, Ihm SH, Park SM, Jung HO, Hong KS, Baek SH, et al. Effects of sarcopenia, body mass indices, and sarcopenic obesity on diastolic function and exercise capacity in Koreans. Metabolism. (2019) 97:1824. doi: 10.1016/j.metabol.2019.05.007

43. Bekfani T, Pellicori P, Morris DA, Ebner N, Valentova M, Steinbeck L, et al. Sarcopenia in patients with heart failure with preserved ejection fraction: impact on muscle strength, exercise capacity and quality of life. Int J Cardiol. (2016) 222:41-6. doi: 10.1016/j.ijcard.2016.07.135
44. Upadhya B, Haykowsky MJ, Eggebeen J, Kitzman DW. Exercise intolerance in heart failure with preserved ejection fraction: more than a heart problem. J Geriatr Cardiol. (2015) 12:294304. doi: 10.11909/j.issn.1671-5411.2015.03.013

45. Trankle C, Canada JM, Buckley L, Carbone S, Dixon D, Arena R, et al. Impaired myocardial relaxation with exercise determines peak aerobic exercise capacity in heart failure with preserved ejection fraction. ESC Heart Fail. (2017) 4:351-5. doi: 10.1002/ehf2.12147

46. Upadhya B, Haykowsky MJ, Eggebeen J, Kitzman DW. Sarcopenic obesity and the pathogenesis of exercise intolerance in heart failure with preserved ejection fraction. Curr Heart Fail Rep. (2015) 12:20514. doi: $10.1007 /$ s11897-015-0257-5

47. Zamani P, Proto EA, Mazurek JA, Prenner SB, Margulies KB, Townsend $\mathrm{RR}$, et al. Peripheral determinants of oxygen utilization in heart failure with preserved ejection fraction: central role of adiposity. JACC Basic Transl Sci. (2020) 5:211-25. doi: 10.1016/j.jacbts.2020.01.003

48. Del Buono MG, Arena R, Borlaug BA, Carbone S, Canada JM, Kirkman DL, et al. Exercise intolerance in patients with heart failure: JACC state-of-the-art review. J Am Coll Cardiol. (2019) 73:2209-25. doi: 10.1016/j.jacc.2019.01.072

49. Lam CSP, Voors AA, de Boer RA, Solomon SD, van Veldhuisen DJ. Heart failure with preserved ejection fraction: from mechanisms to therapies. Eur Heart J. (2018) 39:2780-92. doi: 10.1093/eurheartj/ehy301

50. Michels da Silva D, Langer H, Graf T. Inflammatory and molecular pathways in heart failure-ischemia, HFpEF and transthyretin cardiac amyloidosis. Int J Mol Sci. (2019) 20:2322. doi: 10.3390/ijms20092322

51. Pérez-Baos S, Prieto-Potin I, Román-Blas JA, Sánchez-Pernaute O, Largo R, Herrero-Beaumont G. Mediators and patterns of muscle loss in chronic systemic inflammation. Front Physiol. (2018) 9:409. doi: 10.3389/fphys.2018.00409

52. Kalinkovich A, Livshits G. Sarcopenic obesity or obese sarcopenia: a cross talk between age-associated adipose tissue and skeletal muscle inflammation as a main mechanism of the pathogenesis. Ageing Res Rev. (2017) 35:20021. doi: 10.1016/j.arr.2016.09.008

53. Pellegrinelli V, Rouault C, Rodriguez-Cuenca S, Albert V, Edom-Vovard F, Vidal-Puig A, et al. Human adipocytes induce inflammation and atrophy in muscle cells during obesity. Diabetes. (2015) 64:312134. doi: $10.2337 / \mathrm{db} 14-0796$

54. Zhu S, Tian Z, Torigoe D, Zhao J, Xie P, Sugizaki T, et al. Aging- and obesityrelated peri-muscular adipose tissue accelerates muscle atrophy. PLoS ONE. (2019) 14:e0221366. doi: 10.1371/journal.pone.0221366

55. Lim JP, Leung BP, Ding YY, Tay L, Ismail NH, Yeo A, et al. Monocyte chemoattractant protein-1: a proinflammatory cytokine elevated in sarcopenic obesity. Clin Interv Aging. (2015) 10:605-9. doi: 10.2147/CIA.S78901

56. Schrager MA, Metter EJ, Simonsick E, Ble A, Bandinelli S, Lauretani F, et al. Sarcopenic obesity and inflammation in the InCHIANTI study. J Appl Physiol. (2007) 102:919-25. doi: 10.1152/japplphysiol.00627.2006

57. Bellanti F, Romano AD, Lo Buglio A, Castriotta V, Guglielmi G, Greco A, et al. Oxidative stress is increased in sarcopenia and associated with cardiovascular disease risk in sarcopenic obesity. Maturitas. (2018) 109:612. doi: 10.1016/j.maturitas.2017.12.002

58. D’Amario D, Migliaro S, Borovac JA, Restivo A, Vergallo R, Galli M, et al. Microvascular dysfunction in heart failure with preserved ejection fraction. Front Physiol. (2019) 10:1347. doi: 10.3389/fphys.2019.01347

59. Yang JH, Obokata M, Reddy YNV, Redfield MM, Lerman A, Borlaug BA. Endothelium-dependent and independent coronary microvascular dysfunction in patients with heart failure with preserved ejection fraction. Eur J Heart Fail. (2020) 22:432-41. doi: 10.1002/ejhf.1671

60. Van Tassell BW, Toldo S, Mezzaroma E, Abbate A. Targeting interleukin-1 in heart disease. Circulation. (2013) 128:191023. doi: 10.1161/CIRCULATIONAHA.113.003199

61. Paulus WJ, Tschöpe C. A novel paradigm for heart failure with preserved ejection fraction: comorbidities drive myocardial dysfunction and remodeling through coronary microvascular endothelial inflammation. J Am Coll Cardiol. (2013) 62:263-71. doi: 10.1016/j.jacc.2013.02.092

62. Hage C, Michaëlsson E, Kull B, Miliotis T, Svedlund S, Linde C, et al. Myeloperoxidase and related biomarkers are suggestive footprints of 
endothelial microvascular inflammation in HFpEF patients. ESC Heart Fail. (2020) 7:1534-46. doi: 10.1002/ehf2.12700

63. Brown DA, Perry JB, Allen ME, Sabbah HN, Stauffer BL, Shaikh SR, et al. Expert consensus document: mitochondrial function as a therapeutic target in heart failure. Nat Rev Cardiol. (2017) 14:23850. doi: 10.1038 /nrcardio. 2016.203

64. Millen AME, Woodiwiss AJ, Gomes M, Michel F, Norton GR. Systemic angiotensinogen concentrations are independently associated with left ventricular diastolic function in a community sample. Am J Hypertens. (2018) 31:212-9. doi: 10.1093/ajh/hpx156

65. Negi SI, Jeong EM, Shukrullah I, Veleder E, Jones DP, Fan TH, et al. Renin-angiotensin activation and oxidative stress in early heart failure with preserved ejection fraction. Biomed Res Int. (2015) 2015:825027. doi: 10.1155/2015/825027

66. Myung SK, Ju W, Cho B, Oh SW, Park SM, Koo BK, et al. Efficacy of vitamin and antioxidant supplements in prevention of cardiovascular disease: systematic review and meta-analysis of randomised controlled trials. BMJ. (2013) 346:f10. doi: 10.1136/bmj.f10

67. Favuzzi AMR, Venuti A, Bruno C, Nicolazzi MA, Fuorlo M, Dajko M, et al. Hormonal deficiencies in heart failure with preserved ejection fraction: prevalence and impact on diastolic dysfunction: a pilot study. Eur Rev Med Pharmacol Sci. (2020) 24:352-61. doi: 10.26355/eurrev_202001_19933

68. Salzano A, Cittadini A, Bossone E, Suzuki T, Heaney LM. Multiple hormone deficiency syndrome: a novel topic in chronic heart failure. Future Sci OA. (2018) 4:Fso311. doi: 10.4155/fsoa-2018-0041

69. Faxén UL, Hage C, Benson L, Zabarovskaja S, Andreasson A, Donal E, et al. HFpEF and HFrEF display different phenotypes as assessed by IGF-1 and IGFBP-1. J Card Fail. (2017) 23:293-303. doi: 10.1016/j.cardfail.2016.06.008

70. Hajri T, Tao H, Wattacheril J, Marks-Shulman P, Abumrad NN. Regulation of adiponectin production by insulin: interactions with tumor necrosis factor$\alpha$ and interleukin-6. Am J Physiol Endocrinol Metab. (2011) 300:E35060. doi: 10.1152/ajpendo.00307.2010

71. Savji N, Meijers WC, Bartz TM, Bhambhani V, Cushman M, Nayor M, et al. The association of obesity and cardiometabolic traits with incident HFpEF and HFrEF. JACC Heart Fail. (2018) 6:701-9. doi: 10.1016/j.jchf.2018.05.018

72. Faxén UL, Hage C, Andreasson A, Donal E, Daubert JC, Linde C, et al. HFpEF and HFrEF exhibit different phenotypes as assessed by leptin and adiponectin. Int $J$ Cardiol. (2017) 228:709-16. doi: 10.1016/j.ijcard.2016.11.194

73. Sente T, Van Berendoncks AM, Fransen E, Vrints CJ, Hoymans VY. Tumor necrosis factor- $\alpha$ impairs adiponectin signalling, mitochondrial biogenesis, and myogenesis in primary human myotubes cultures. Am J Physiol Heart Circ Physiol. (2016) 310:H1164-75. doi: 10.1152/ajpheart.00831.2015

74. Singh P, Sharma P, Sahakyan KR, Davison DE, Sert-Kuniyoshi FH, Romero-Corral A, et al. Differential effects of leptin on adiponectin expression with weight gain versus obesity. Int J Obes. (2016) 40:26674. doi: 10.1038/ijo.2015.181

75. Calvani R, Joseph AM, Adhihetty PJ, Miccheli A, Bossola M, Leeuwenburgh C, et al. Mitochondrial pathways in sarcopenia of aging and disuse muscle atrophy. Biol Chem. (2013) 394:393-414. doi: 10.1515/hsz-2012-0247

76. Del Campo A, Contreras-Hernandez I, Castro-Sepulveda M, Campos CA, Figueroa R, Tevy MF, et al. Muscle function decline and mitochondria changes in middle age precede sarcopenia in mice. Aging. (2018) 10:3455. doi: 10.18632 /aging. 101358

77. Van Tassell BW, Trankle CR, Canada JM, Carbone S, Buckley L, Kadariya D, et al. IL-1 blockade in patients with heart failure with preserved ejection fraction. Circ Heart Fail. (2018) 11:e005036. doi: 10.1161/CIRCHEARTFAILURE.118.005036

78. DuBrock HM, AbouEzzeddine OF, Redfield MM. High-sensitivity C-reactive protein in heart failure with preserved ejection fraction. PLoS ONE. (2018) 13:e0201836. doi: 10.1371/journal.pone.0201836

79. Molina AJ, Bharadwaj MS, Van Horn C, Nicklas BJ, Lyles MF, Eggebeen J, et al. Skeletal muscle mitochondrial content, oxidative capacity, and Mfn2 expression are reduced in older patients with heart failure and preserved ejection fraction and are related to exercise intolerance. JACC Heart Fail. (2016) 4:636-45. doi: 10.1016/j.jchf.2016.03.011
80. Hummel SL, Mitchell SE, Brook RD, Kolias TJ, Sheth SS, Rosenblum RH, et al. Low-sodium dietary approaches to stop hypertension diet reduces blood pressure, arterial stiffness, and oxidative stress in hypertensive heart failure with preserved ejection fraction. Hypertension. (2012) 60:12006. doi: 10.1161/HYPERTENSIONAHA.112.202705

81. Bishu K, Deswal A, Chen HH, LeWinter MM, Lewis GD, Semigran $\mathrm{MJ}$, et al. Biomarkers in acutely decompensated heart failure with preserved or reduced ejection fraction. Am Heart J. (2012) 164:76370.e3. doi: 10.1016/j.ahj.2012.08.014

82. Szendroedi J, Phielix E, Roden M. The role of mitochondria in insulin resistance and type 2 diabetes mellitus. Nat Rev Endocrinol. (2011) 8:92103. doi: $10.1038 /$ nrendo.2011.138

83. Beale AL, Warren JL, Roberts N, Meyer P, Townsend NP, Kaye D. Iron deficiency in heart failure with preserved ejection fraction: a systematic review and meta-analysis. Open Heart. (2020) 6:e001012. doi: 10.1136/openhrt-2019-001012

84. McDonagh T, Macdougall IC. Iron therapy for the treatment of iron deficiency in chronic heart failure: intravenous or oral? Eur J Heart Fail. (2015) 17:248-62. doi: 10.1002/ejhf.236

85. Klip IT, Voors AA, Swinkels DW, Bakker SJ, Kootstra-Ros JE, Lam CS, et al. Serum ferritin and risk for new-onset heart failure and cardiovascular events in the community. Eur J Heart Fail. (2017) 19:348-56. doi: 10.1002/ejhf.622

86. Wong CC, Ng AC, Kritharides L, Sindone AP. Iron deficiency in heart failure: looking beyond anaemia. Heart Lung Circ. (2016) 25:20916. doi: $10.1016 /$ j.hlc.2015.06.827

87. Martens P, Nijst P, Verbrugge FH, Smeets K, Dupont M, Mullens W. Impact of iron deficiency on exercise capacity and outcome in heart failure with reduced, mid-range and preserved ejection fraction. Acta Cardiol. (2018) 73:115-23. doi: 10.1080/00015385.2017.1351239

88. Bekfani T, Pellicori P, Morris D, Ebner N, Valentova M, Sandek A, et al. Iron deficiency in patients with heart failure with preserved ejection fraction and its association with reduced exercise capacity, muscle strength and quality of life. Clin Res Cardiol. (2019) 108:203-11. doi: 10.1007/s00392-018-1344-x

89. Rariden BS, Boltz AJ, Brawner CA, Pinkstaff SO, Richardson MR, Johnson $\mathrm{TM}$, et al. Sedentary time and cumulative risk of preserved and reduced ejection fraction heart failure: from the multi-ethnic study of atherosclerosis. J Card Fail. (2019) 25:418-24. doi: 10.1016/j.cardfail.2019.03.017

90. Lee DC, Shook RP, Drenowatz C, Blair SN. Physical activity and sarcopenic obesity: definition, assessment, prevalence and mechanism. Future Sci OA. (2016) 2:FSO127. doi: 10.4155/fsoa-2016-0028

91. Tucker WJ, Nelson MD, Beaudry RI, Halle M, Sarma S, Kitzman DW, et al. Impact of exercise training on peak oxygen uptake and its determinants in heart failure with preserved ejection fraction. Card Fail Rev. (2016) 2:95-101. doi: 10.15420/cfr.2016:16:2

92. Balducci S, D'Errico V, Haxhi J, Sacchetti M, Orlando G, Cardelli P, et al. Effect of a behavioral intervention strategy on sustained change in physical activity and sedentary behavior in patients with type 2 diabetes: the IDES_2 randomized clinical trial. JAMA. (2019) 321:88090. doi: 10.1001/jama.2019.0922

93. Mauricio R, Patel KV, Agusala V, Singh K, Lewis A, Ayers C, et al. Sex differences in cardiac function, biomarkers and exercise performance in heart failure with preserved ejection fraction: findings from the RELAX trial. Eur J Heart Fail. (2019) 21:1476-9. doi: 10.1002/ejhf.1554

94. Haykowsky MJ, Brubaker PH, Stewart KP, Morgan TM, Eggebeen J, Kitzman DW. Effect of endurance training on the determinants of peak exercise oxygen consumption in elderly patients with stable compensated heart failure and preserved ejection fraction. J Am Coll Cardiol. (2012) 60:1208. doi: 10.1016/j.jacc.2012.02.055

95. Taylor RS, Davies EJ, Dalal HM, Davis R, Doherty P, Cooper C, et al. Effects of exercise training for heart failure with preserved ejection fraction: a systematic review and meta-analysis of comparative studies. Int J Cardiol. (2012) 162:6-13. doi: 10.1016/j.ijcard.2012.05.070

96. Holland DJ, Kumbhani DJ, Ahmed SH, Marwick TH. Effects of treatment on exercise tolerance, cardiac function, and mortality in heart failure with preserved ejection fraction. A meta-analysis. J Am Coll Cardiol. (2011) 57:1676-86. doi: 10.1016/j.jacc.2010.10.057 
97. Donelli da Silveira A, Beust de Lima J, da Silva Piardi D, Dos Santos Macedo D, Zanini M, Nery R, et al. High-intensity interval training is effective and superior to moderate continuous training in patients with heart failure with preserved ejection fraction: a randomized clinical trial. Eur J Prev Cardiol. (in press) doi: 10.1177/2047487319901206

98. Shaltout HA, Eggebeen J, Marsh AP, Brubaker PH, Laurienti PJ, Burdette JH, et al. Effects of supervised exercise and dietary nitrate in older adults with controlled hypertension and/or heart failure with preserved ejection fraction. Nitric Oxide. (2017) 69:78-90. doi: 10.1016/j.niox.2017.05.005

99. Edelmann F, Gelbrich G, Dungen HD, Frohling S, Wachter R, Stahrenberg $\mathrm{R}$, et al. Exercise training improves exercise capacity and diastolic function in patients with heart failure with preserved ejection fraction: results of the Ex-DHF (exercise training in diastolic heart failure) pilot study. J Am Coll Cardiol. (2011) 58:1780-91. doi: 10.1016/j.jacc.2011.06.054

100. Haykowsky MJ, Kouba EJ, Brubaker PH, Nicklas BJ, Eggebeen J, Kitzman DW. Skeletal muscle composition and its relation to exercise intolerance in older patients with heart failure and preserved ejection fraction. Am J Cardiol. (2014) 113:1211-6. doi: 10.1016/j.amjcard.2013.12.031

101. Pu CT, Johnson MT, Forman DE, Hausdorff JM, Roubenoff R, Foldvari $\mathrm{M}$, et al. Randomized trial of progressive resistance training to counteract the myopathy of chronic heart failure. J Appl Physiol. (2001) 90:234150. doi: 10.1152/jappl.2001.90.6.2341

102. Lemmey AB, Marcora SM, Chester K, Wilson S, Casanova F, Maddison PJ. Effects of high-intensity resistance training in patients with rheumatoid arthritis: a randomized controlled trial. Arthritis Rheum. (2009) 61:172634. doi: 10.1002/art.24891

103. Marcora SM, Lemmey AB, Maddison PJ. Can progressive resistance training reverse cachexia in patients with rheumatoid arthritis? Results of a pilot study. J Rheumatol. (2005) 32:1031-9. Available online at: https://pubmed. ncbi.nlm.nih.gov/15940763/

104. Kirkman DL, Mullins P, Junglee NA, Kumwenda M, Jibani MM, Macdonald JH. Anabolic exercise in haemodialysis patients: a randomised controlled pilot study. J Cachexia Sarcopenia Muscle. (2014) 5:199207. doi: 10.1007/s13539-014-0140-3

105. Carbone S, Billingsley HE, Abbate A. The mediterranean diet to treat heart failure: a potentially powerful tool in the hands of providers. JACC Heart Fail. (2018) 6:264. doi: 10.1016/j.jchf.2017.12.008

106. Isanejad M, Sirola J, Mursu J, Rikkonen T, Kroger H, Tuppurainen M, et al. Association of the baltic sea and mediterranean diets with indices of sarcopenia in elderly women, OSPTRE-FPS study. Eur J Nutr. (2018) 57:1435-48. doi: 10.1007/s00394-017-1422-2

107. Abete I, Konieczna J, Zulet MA, Galmés-Panades AM, Ibero-Baraibar I, Babio $\mathrm{N}$, et al. Association of lifestyle factors and inflammation with sarcopenic obesity: data from the PREDIMED-Plus trial. J Cachexia Sarcopenia Muscle. (2019) 10:974-84. doi: 10.1002/jcsm.12442

108. Hashemi R, Motlagh AD, Heshmat R, Esmaillzadeh A, Payab M, Yousefinia $\mathrm{M}$, et al. Diet and its relationship to sarcopenia in community dwelling Iranian elderly: a cross sectional study. Nutrition. (2015) 31:97104. doi: 10.1016/j.nut.2014.05.003

109. Miró Ò, Estruch R, Martín-Sánchez FJ, Gil V, Jacob J, Herrero-Puente P, et al. Adherence to mediterranean diet and all-cause mortality after an episode of acute heart failure: results of the MEDIT-AHF study. JACC Heart Fail. (2018) 6:52-62. doi: 10.1016/j.jchf.2017.09.020

110. Carbone S, Canada JM, Buckley LF, Trankle CR, Billingsley HE, Dixon DL, et al. Dietary fat, sugar consumption, and cardiorespiratory fitness in patients with heart failure with preserved ejection fraction. JACC Basic Transl Sci. (2017) 2:513-25. doi: 10.1016/j.jacbts.2017.06.009

111. Carbone S, Billingsley HE, Canada JM, Kadariya D, Medina de Chazal H, Rotelli B, et al. Unsaturated fatty acids to improve cardiorespiratory fitness in patients with obesity and HFpEF: the UFA-preserved pilot study. JACC Basic Transl Sci. (2019) 4:563-5. doi: 10.1016/j.jacbts.2019.04.001
112. Hummel SL, Seymour EM, Brook RD, Sheth SS, Ghosh E, Zhu S, et al. Low-sodium DASH diet improves diastolic function and ventricular-arterial coupling in hypertensive heart failure with preserved ejection fraction. Circ Heart Fail. (2013) 6:1165-71. doi: 10.1161/CIRCHEARTFAILURE.113.000481

113. Hummel SL, Karmally W, Gillespie BW, Helmke S, Teruya $\mathrm{S}$, Wells J, et al. Home-delivered meals postdischarge from heart failure hospitalization. Circ Heart Fail. (2018) 11:e004886. doi: 10.1161/CIRCHEARTFAILURE.117.004886

114. Nabuco HCG, Tomeleri CM, Fernandes RR, Sugihara Junior P, Cavalcante EF, Cunha PM, et al. Effect of whey protein supplementation combined with resistance training on body composition, muscular strength, functional capacity, and plasma-metabolism biomarkers in older women with sarcopenic obesity: a randomized, double-blind, placebo-controlled trial. Clin Nutr ESPEN. (2019) 32:88-95. doi: 10.1016/j.clnesp.2019.04.007

115. Vest AR, Chan M, Deswal A, Givertz MM, Lekavich C, Lennie $\mathrm{T}$, et al. Nutrition, obesity, and cachexia in patients with heart failure: a consensus statement from the heart failure society of America scientific statements committee. J Card Fail. (2019) 25:380-400. doi: 10.1016/j.cardfail.2019.03.007

116. Aquilani R, Opasich C, Gualco A, Verri M, Testa A, Pasini E, et al. Adequate energy-protein intake is not enough to improve nutritional and metabolic status in muscle-depleted patients with chronic heart failure. Eur J Heart Fail. (2008) 10:1127-35. doi: 10.1016/j.ejheart.2008.09.002

117. Pineda-Juarez JA, Sanchez-Ortiz NA, Castillo-Martinez L, Orea-Tejeda A, Cervantes-Gaytan R, Keirns-Davis C, et al. Changes in body composition in heart failure patients after a resistance exercise program and branched chain amino acid supplementation. Clin Nutr. (2016) 35:417. doi: 10.1016/j.clnu.2015.02.004

118. Abbate A, Toldo S, Marchetti C, Kron J, Van Tassell BW, Dinarello CA. Interleukin-1 and the inflammasome as therapeutic targets in cardiovascular disease. Circ Res. (2020) 126:126080. doi: 10.1161/CIRCRESAHA.120.315937

119. Van Tassell BW, Arena R, Biondi-Zoccai G, Canada JM, Oddi C, Abouzaki NA, et al. Effects of interleukin-1 blockade with anakinra on aerobic exercise capacity in patients with heart failure and preserved ejection fraction (from the D-HART pilot study). Am J Cardiol. (2014) 113:3217. doi: 10.1016/j.amjcard.2013.08.047

120. Zamani P, Rawat D, Shiva-Kumar P, Geraci S, Bhuva R, Konda $\mathrm{P}$, et al. Effect of inorganic nitrate on exercise capacity in heart failure with preserved ejection fraction. Circulation. (2015) 131:37180. doi: 10.1161/CIRCULATIONAHA.114.012957

121. Borlaug BA, Koepp KE, Melenovsky V. Sodium nitrite improves exercise hemodynamics and ventricular performance in heart failure with preserved ejection fraction. J Am Coll Cardiol. (2015) 66:1672-82. doi: 10.1016/j.jacc.2015.07.067

122. Borlaug BA, Melenovsky V, Koepp KE. Inhaled sodium nitrite improves rest and exercise hemodynamics in heart failure with preserved ejection fraction. Circ Res. (2016) 119:880-6. doi: 10.1161/CIRCRESAHA.116.309184

Conflict of Interest: The authors declare that the research was conducted in the absence of any commercial or financial relationships that could be construed as a potential conflict of interest.

Copyright (C) 2020 Kirkman, Bohmke, Billingsley and Carbone. This is an open-access article distributed under the terms of the Creative Commons Attribution License (CC $B Y)$. The use, distribution or reproduction in other forums is permitted, provided the original author(s) and the copyright owner(s) are credited and that the original publication in this journal is cited, in accordance with accepted academic practice. No use, distribution or reproduction is permitted which does not comply with these terms. 